\title{
Multicenter phase II trial of brequinar sodium in patients with advanced squamous-cell carcinoma of the head and neck
}

\author{
Susan Urba1, James Doroshow ${ }^{2}$, Christine Cripps ${ }^{3}$, Francisco Robert ${ }^{4 *}$, Enrique Velez-Garcia ${ }^{5}$, Brian Dallaire ${ }^{6}$, \\ David Adams, 6 , Randall Carlson 6 , Antonio Grillo-Lopez ${ }^{1,6}$, John Gyves $^{6}$ \\ I University of Michigan, Ann Arbor, MI, USA \\ 2 City of Hope National Medical Center, Duarte, CA, USA \\ 3 Ottawa Regional Cancer Center, Ottawa, Ontario, Canada \\ ${ }^{4}$ San Juan Veterans' Hospital, San Juan, PR, USA \\ 5 University of Puerto Rico School of Medicine, San Juan, Puerto Rico, USA \\ 6 The DuPont Pharmaceutical Co., Wilmington, DE, USA
}

Received 20 March 1992/Accepted 24 June 1992

\begin{abstract}
A total of 19 patients with advanced squamouscell carcinoma of the head and neck who had not previously been exposed to chemotherapy were treated with brequinar sodium as first-line chemotherapy. Brequinar was given intravenously at a median weekly dose of $1,200 \mathrm{mg} / \mathrm{m}^{2}$. The toxicity was moderate, with 7 patients (37\%) experiencing grade 3 or 4 toxicity. In all, 16 patients who were evaluable for efficacy showed no objective response. We conclude that brequinar given at this dose and on this schedule has no significant activity in advanced squamous-cell carcinoma of the head and neck.
\end{abstract}

\section{Introduction}

Brequinar sodium is a novel antimetabolite that interferes with dihydrooratate dehydrogenase, and enzyme that is crucial for pyrimidine biosynthesis [4]. Brequinar was selected for clinical development because of its broad antitumor activity in murine models (L1210 leukemia and B16 melanoma) and human tumor xenografts [breast (MX-1), colon (CX-1), lung (LX-1), and gastric (BL/STX-1)] [7].

A number of phase I studies using different dose levels and schedules have been reported $[1-3,5,8,9]$. In these phase I studies, the limiting toxicities included thrombocytopenia and mucositis/stomatitis. Minor responses were seen in advanced bladder, lung, lymphoma, and thyroid carcinoma $[3,5,9]$. The weekly schedule was selected for phase II evaluation because of the superior dose intensity

This study was supported by DuPont Pharmaceutical Company (Wilmington, Del., USA)

* Current affiliation University of Alabama at Birmingham, Birmingham, AL, USA

Correspondence to: J. W. Gyves, Department of Oncology The DuPont Merck Pharmaceutical Company, P. O. Box 80026, P26/1160, Wilmington, DE 19880-0026. USA achieved in comparison with that previously obtained on the phase I schedules. In addition, the pharmacokinetic profite indicated a half-life of $15 \mathrm{~h}$, resulting in prolonged drug exposure when this schedule was used [3]. Preclinical studies also suggested that efficacy was achieved by prolonged exposure $[7,11]$.

On the basis of the phase I experience, the recommended phase II starting dose and schedule was $1,800 \mathrm{mg} / \mathrm{m}^{2}$ weekly $[3,5]$. Early in the phase II evaluation of brequinar in several tumor categories, this starting dose resulted in unacceptable toxicity [6]. Therefore, the starting dose was reduced to $1,200 \mathrm{mg} / \mathrm{m}^{2}$ weekly.

The present multicenter study was designed to evaluate the activity of brequinar in patients with advanced squamous-cell carcinoma of the head and neck who had received no prior chemotherapy.

\section{Patients and methods}

The criteria for inclusion in the study were a performance status of $\leq 2$ (WHO scale), a life expectancy of $>8$ weeks, a serum bilinbin value of $<1.5 \mathrm{mg} / \mathrm{dl}$, a serum creatinine level of $<2.0 \mathrm{mg} / \mathrm{dl}$, an absolute granulocyte count of $>1,500$ cells $/ \mathrm{mm}^{3}$, a platelet count of $>100,000 / \mathrm{mm}^{3}$, and the presence of bidimensionally measurable disease. Informed consent was given by all patients in accordance with regulatory agency requirements.

Brequinar was given intravenously once weekly at a starting dose of $1,200 \mathrm{mg} / \mathrm{m}^{2}$ in $500 \mathrm{ml}$ normal saline over $\mathbf{l}-2 \mathrm{~h}$. The dose of brequinar was escalated or decreased according to predetermined criteria and depending on the toxicities experienced during the preceding course. When necessary, dosing was delayed until the patient had recovered from toxicities. Toxicity was coded by $\mathrm{NCI}$ common toxicity criteria $(2 / 18 / 88$ version).

Patients were interviewed and examined prior to each dose of chemotherapy. Laboratory studies, including complete blood cell, differential, and platelet counts, were repeated once a week. Total protein, albumin, calcium, inorganic phosphorus, glucose, blood urea nitrogen, creatinine, uric acid, total bilirubin, alkaline phosphatase, lactic dehydrogenase, and electrolytes were assessed every 4 weeks.

Response was evaluated every 4 weeks by appropriate radiologic studies and clinical measurement of bidimensional lesions. Criteria for defining response were standard except that a palpable reduction in liver size was not used to designate a partial response. Patients were consid- 
Table 1. Patient's characteristics and treatment data

\begin{tabular}{ll}
\hline Total patients & 19 \\
Evaluable patients & 16 \\
Sex (M/F) & $15 / 4$ \\
Median age (years) & 59 (range, 44-77) \\
Performance status ${ }^{\mathrm{a}}$ & \\
$\quad$ Median & 1 \\
$\quad$ Range & $0-2$ \\
Prior therapy: & \\
$\quad$ Surgery & 15 \\
$\quad$ Radiation therapy & 18 \\
Sites of metastases & \\
$\quad$ Lymph nodes & $2(11 \%)$ \\
$\quad$ Bone & $2(11 \%)$ \\
Lung & $5(26 \%)$ \\
$\quad$ Mediastinum & $1(5 \%)$ \\
$\quad$ Skin/subcutaneous tissue & $5(26 \%)$ \\
Other & $3(16 \%)$ \\
Number of doses given: & \\
Total & 104 \\
Median & 4 \\
Range & $1-17$ \\
Number of patients receiving: & \\
Dose escalation & 5 \\
Dose reduction & 4 \\
\hline
\end{tabular}

a WHO [12]

ered to be evaluable for response if they had received at least one dose of brequinar and had undergone a subsequent assessment of their measurable disease. Patients who died of their disease without undergoing such an assessment were considered to be evaluable and classified as having progressive disease.

\section{Results}

From November 1988 to June 1989,19 patients with advanced squamous-cell carcinoma of the head and neck entered in the study. Data on the patients and their treatment characteristics are listed in Table 1 . The patients had an excellent performance status and limited exposure to prior therapy. The predominant sites of measurable disease were the lung and the skin/subcutaneous tissue. The 19 patients, received a total of 104 doses of brequinar (median, 4; range, 1-17). Dose escalation was possible in five patients and dose reduction was required in four cases. Two patients received only one dose. The median weekly dose was $1,200 \mathrm{mg} / \mathrm{m}^{2}$.

Of the 19 patients entered in the study, 16 were evaluable for response; 1 patient each was deemed inevaluable due to the absence of a measurable lesion, to early non-disease-related death, and to our inability to obtain follow-up measurements. No objective response was observed, and eight patients displayed stabilization of their disease.

All 19 patients were evaluable for toxicity. In general, the toxicity encountered in this phase II trial was moderate. The major nonhematologic and hematologic toxicities encountered are listed in Table 2. No drug-related death occurred. However, two patients were removed from the
Table 2. Toxicity encountered in the present study

\begin{tabular}{lllll}
\hline Toxic effect & \multicolumn{4}{l}{ Number of patients by maximal grade } \\
\cline { 2 - 5 } & Grade 1 & Grade 2 & Grade 3 & Grade 4 \\
\hline Nausea/vomiting & 5 & 5 & 0 & 0 \\
Mucositis/stomatitis & 9 & 1 & 3 & 0 \\
Rash & 6 & 0 & 0 & 1 \\
Diarrhea & 2 & 2 & 0 & 1 \\
Thrombocytopenia & 3 & 1 & 4 & 1 \\
Anemia & 2 & 5 & 1 & 0 \\
Leukopenia & 3 & 6 & 0 & 0 \\
Granulocytopenia & 1 & 1 & 0 & 0 \\
\hline
\end{tabular}

study because of grade 4 toxicities. One patient experienced grade 4 diarrhea and thrombocytopenia after four doses; this patient received a cumulative brequinar dose of $7,200 \mathrm{mg}$. The second patient experienced a grade 4 rash after the second dose (cumulative dose, $2,400 \mathrm{mg}$ ). The rash associated with high-dose intermittent administration of brequinar has been described elsewhere [10].

Eight episodes of grade 3 toxicity occurred in five patients. Six of the seven patients who experienced grade $3-4$ toxicity did so during the first four weekly doses. The patients who experienced grade $3-4$ toxicity received a median of 3 doses (range, 1-9), whereas those who did not develop grade 3-4 toxicity received a median of 6 doses (range, 1-17). The median weekly dose given to these seven patients was $1,378 \mathrm{mg} / \mathrm{m}^{2}$ (range, 972$1,800 \mathrm{mg} / \mathrm{m}^{2}$ ) and the median cumulative dose was $3,817 \mathrm{mg}$ (range, 1,200-17,064 mg). The corresponding doses for the patients who experienced toxicity graded $\leq 2$ were a median weekly dose of $1,200 \mathrm{mg} / \mathrm{m}^{2}$ (range, 960 $2,160 \mathrm{mg} / \mathrm{m}^{2}$ ) and a median cumulative dose of $6,910 \mathrm{mg}$ (range, 1,200-20,400 mg).

In all, 11 patients discontinued therapy because of disease progression. The remaining patients were removed from treatment for the following reasons: grade 4 toxicity $(n=2)$, non-disease-related death $(n=1)$, loss to follow-up $(n=1)$, refusal of further therapy $(n=2)$, and stabilization of disease after 12 weeks of therapy $(n=2)$.

\section{Discussion}

The absence of objective responses in 16 evaluable patients excludes (with 95\% confidence) a response rate of $20 \%$ (one-sided $95 \%$ confidence limit, 17.1\%). On the basis of these results, we conclude that brequinar given at this dose and on this schedule does not have sufficient activity to warrant further evaluation in patients with advanced squamous-cell carcinoma of the head and neck.

\section{References}

1. Armand J, Fontana X, DeForni M, Carde P, Munck N, Cvitkovic E, Malet Martino MC (1987) A phase I study of DuP 785 (NSC 368 390) using a 5 daily IV schedule. Proc Am Soc Clin Oncol 6: 46 
2. Arteaga C, Brown T, Kuhn J, Shen H, O'Rourke T, Beougher K, Brentzel H, Von Hoff D, Weiss G (1989) Phase I clinical and pharmacokinetic trial of brequinar sodium (DuP 785; NSC 368390). Cancer Res 49: 4648-4653

3. Bork E, Vest S, Hansen H (1989) A phase I clinical and pharmacokinetic study of brequinar sodium, DuP 785 (NSC 368390), using a weekly and a biweekly schedule. Eur J Clin Oncol 25: 1403-1411

4. Chen S, Ruben R, Dexter D (1986) Mechanism of action of the novel anticancer agent 6-fluoro-2-(2'-fluoro-1,1'-biphenyl-4-yl)-3-methyl4-quinolinecarboxylic acid sodium salt (NSC 368 390): inhibition of de novo pyrimidine nucleotide biosynthesis. Cancer Res 46: 5014-5019

5. Currie V, O'Hehir M, Baltzer L, Slavik W, Yaldaei S, Bertino J (1988) Phase I trial of DuP 785 given on a single weekly intravenous dosing schedule. Proc Am Soc Clin Oncol 7: 76

6. Dallaire B, Varns C, Galbraith D, Wielgosz G, Adams D, Brentzel H, Lynch W, Carlson R, Sisk R, Azarnia N, Bigelow R, Barbu M, Gyves J, Grillo-Lopez A (1991) Preliminary report of safety for a phase I trial of brequinar sodium (DuP 785, NSC 368390) in refractory solid tumors. Clin Res 39: 375 A

7. Dexter D, Hesson D, Ardecky R, Rao G, Tippett D, Dusak B, Paull K, Plowman J, DeLarco B, Narayanan V, Forbes M (1985) Activity of a novel 4-quinolinecarboxylic acid, NSC 368390 [6-fluoro- 2-(2'-fluoro-1,1'-biphenyl-4-y])-3-methyl-4-quinolinecar boxylic acid sodium salt], against experimental tumors. Cancer Res 45: $5563-5568$

8. Noe D, Rowinsky E, Shen H, Clarke B, Grochow L, McGuire W, Hantel A, Adams D, Abeloff M, Ettinger D, Donehower R (1990) Phase I and pharmacokinetic study of brequinar sodium (NSC 368 390). Cancer Res 50: 4595-4599

9. Schwartsmann G, Dodion P, Vermorken J, Bokkel Huinink W ten, Joggi J, Winograd B, Gall H, Simonetti G, Vijgh W van der, Hennik $M$ van, Crespeigne N, Pindo H (1990) Phase I study of DuP 785 (NSC 368930 ) in solid tumors. Cancer Chemother Pharmacol 25: $345-351$

10. Schwartsmann G, Bork E, Vermorken J, Nieboer C, Dodion P, Bokkel Huinink W ten, Seldenrijk C, Armand J, Pinedo H (1989) Mucocutaneous side effects of brequinar sodium: a new inhibitor of pyrimidine de novo biosynthesis. Cancer 63: 243-428

11. Schwartsmann G, Peters G, Laurensse E, DeWaal F, Loonen A, Leyva H, Pinedo H (1988) DuP 785 (NSC 368390): schedule dependency of growth-inhibitory and antipyrimidine effects. Biochem Pharmacol 37: $3257-3266$

12. WHO (1979) Handbook for reporting results of cancer treatment Publication 45. WHO, Geneva 